\title{
A EVOLUÇÃO DO TRABALHO: DA PRÉ-HISTÓRIA ATÉ AO TELETRABALHO
}

\author{
Clarissa Peres Fontana
}

RESUMO: a evolução do trabalho apresenta uma constante especialização no que se refere ao uso de tecnologias. Ao considerar a história do trabalho, revela-se que este fazer humano transformou não apenas a relação da humanidade com os objetos e processos da realidade, bem como as interações sociais e a construção dos modelos civilizacionais do presente. Se na pré-história e na antiguidade o trabalho surge como uma necessidade de sobrevivência e proteção, na contemporaneidade se revela difuso, especializado e profundamente tecnológico. A Idade Média somou os conhecimentos acumulados das eras anteriores à utilização de elementos mecânicos, propiciando um novo patamar para o trabalho que passa a utilizar-se de tecnologias que o aceleram e o avolumam, culminando na Revolução Industrial e seus desdobramentos até a atualidade. O teletrabalho apresenta-se como uma evolução do próprio fazer humano que sempre utilizou os elementos da realidade e as forças naturais para usufruir ou transformar distintos elementos. Da máquina a vapor medieval e dos motores que utilizam combustíveis fósseis, evolui-se para as redes de comunicação e informação como o telégrafo e o telefone, e posteriormente os computadores e a Internet. A Internet transforma-se em uma extensão virtual ou digital da realidade física, oferecendo novas ferramentas para o fazer humano. Considerando a tecnologia, os computadores e as redes elementos da realidade criados pela ação humana, estes elementos se transformam em ferramentas ou processos para criar ou modificar outros processos ou realidades físicas ou digitais. Assim, o teletrabalho hoje não apenas é um fazer virtualizado ou digital, como também é uma ferramenta para a geração de novos elementos da realidade humana, conformada em um hibridismo entre o físico e o digital.

Palavras-chave: Trabalho. Teletrabalho. Tecnologia.

ABSTRACT: the evolution of the work presents a constant specialization regarding the use of technologies. When considering the history of work, it is revealed that this human making has transformed not only humanity's relationship with the objects and processes of reality, as well as social interactions and the construction of present-day civilizational models. If in prehistory and antiquity work appears as a need for survival and protection, nowadays it is diffuse, specialized and deeply technological. The Middle Ages added the knowledge accumulated from the eras prior to the use of mechanical elements, providing a new level for work that starts to use technologies that accelerate and increase it, culminating in the Industrial Revolution and its developments to the present day. Telework presents

I Licenciada em Pedagogia e pós-graduada em Educação Especial. Faculdade de Carapicuíba- SP. E-mail: fontana@hotmail.com. 
itself as an evolution of the human making itself that has always used the elements of reality and natural forces to enjoy or transform different elements. From the medieval steam engine and engines that use fossil fuels, it evolved to communication and information networks such as the telegraph and telephone, and later to computers and the Internet. The Internet becomes a virtual or digital extension of physical reality, offering new tools for human making. Considering technology, computers and networks as elements of reality created by human action, these elements become tools or processes to create or modify other processes or physical or digital realities. Thus, telework today is not only a virtualized or digital activity, but it is also a tool for the generation of new elements of human reality, conformed in a hybridism between the physical and the digital.

keywords: work. telework. technology.

\section{INTRODUÇÃO}

As mudanças no trabalho desde o fim da Idade Média até à modernidade foram inúmeras. Tais mudanças não só alteraram a forma como se compreende e se executa o trabalho, bem como por meio do próprio trabalho, a sociedade sofreu um processo de ressignificação de paradigmas sociais.

O contexto contemporâneo é para as empresas marcado pela alta competitividade,

busca de novos mercados, processos e modelos de negócios. O avanço tecnológico das últimas eras, o incremento da ciência computacional, a mecatrônica e a robótica trouxeram ao ambiente corporativo novas ferramentas na busca de otimizar os processos internos, da gestão à produção. $O$ mesmo se compreende à outras atividades que puderam ser virtualizadas, como o teletrabalho.

O trabalho pode ser considerado uma ação humana na transformação de objetos e processos, instrumentalizando-os no sentido de uma finalidade. Esta ação humana de transformação sofreu ao longo do tempo uma série de modificações e evoluções culminando, na contemporaneidade, na digitalização e virtualização de inúmeros processos. Entretanto, é relevante rever estas alterações históricas sempre na perspectiva de considerar o trabalho e os processos a ele relacionados como dinâmicos e em contínua transformação e ressignificação.

Segundo Martins (2000, p. 168) a palavra trabalho vem "do latim "tripalium" que era uma espécie de instrumento de tortura ou uma canga que pesava sobre os animais." Veschi (2019), e Bastos, Pinho e Costa (1995) fazem a mesma consideração acerca da origem da 
palavra trabalho, como sendo um objeto de tortura e castigo. Já para Lara (2019) e em um artigo da Universidade Federal do Rio Grande do Sul (UFRGS, 202I) o tripalium era um instrumento utilizado na lavoura. Independentemente da origem exata da palavra trabalho, o que se pode perceber é que o mesmo se relaciona com o conceito de uma ação humana.

Os autores que apresentam a origem da palavra trabalho como sendo relacionada à castigo e tortura, podem querer justificar a percepção contemporânea de alguns segmentos sociais do trabalho como algo penoso. Também costuma-se relacionar o texto bíblico do livro de Gêneses capítulo 3, versículo 17, que aponta o trabalho como um possível castigo à desobediência humana, "em fadigas obterás dela o teu sustento durante os dias de tua vida" (BÍBLIA, 1969).

Não é o objetivo deste artigo definir se tripalium era um instrumento de castigo ou ferramenta de trabalho, tampouco considerar se o trabalho é compreendido como algo penoso ou não, o que, de certa forma, não se sustenta na contemporaneidade pela variação dos modelos de trabalho e a presença da tecnologia, outrossim, cabe considerar que o trabalho pode ter surgido em um contexto pré-histórico.

\section{DESENVOLVIMENTO}

Na pré-História, o Paleolítico foi um período histórico de longa duração considerado de 2,6 milhões de anos atrás até o ano ro mil a.C. Foi neste período que se registram as artes rupestres, esculturas e pequenas ferramentas obtidas pela quebra de pedras. Por isso o período é conhecido como o da "pedra lascada", ou seja, as lascas obtidas pela quebra de certas pedras destinavam-se a artefatos, armas e ferramentas. Nisto, se pode considerar que as primeiras ações humanas relacionadas a transformação da realidade, também são os primeiros trabalhos (CAIUSCA, 2019; ROSA; ZINGANO, 2013).

Para aprofundar tal percepção, é oportuno considerar então a concepção moderna da palavra trabalho. Conforme o entendimento de Neves et al. (2017) e Pereira (2021) o trabalho é considerado uma atuação do homem na modificação sobre os diferentes objetos ou processos relacionados a vida.

O interessante da concepção Neves et al. (2018) na compreensão moderna do trabalho é a percepção dele como uma atividade profissional (requer uma habilidade) remunerada ou 
não. Considerando o entendimento dos autores como correto, não haveria problemas de assumir a atividade pré-histórica como uma primeira forma de trabalho, visto que necessitava de uma determinada habilidade na criação de utensílios, armas e ferramentas, bem como a remuneração era relacionada a satisfação de necessidades fisiológicas ou psicológicas.

Já no período de ıo mil anos a.C., até 4 mil anos a.C., há uma transformação dos processos humanos de modificação da realidade, ou, como será chamada doravante, dos trabalhos realizados pelos seres humanos. O período histórico é conhecido como Neolítico ou como o período da "pedra polida" ou "nova pedra". O trabalho humano de modificação da realidade se altera e se especializa, não contentando-se mais com os subprodutos das lascas de pedras, mas polindo-as ou (refinando, afiando) no sentido de obter objetos mais precisos. Há uma especialização deste trabalho humano voltado a subsistência, com um aprimoramento do processo ou uma origem das primeiras tecnologias.

Foi neste período que ocorreu a Revolução Agrícola, pois a humanidade passou de uma configuração nômade para sedentária, fixando-se em áreas com um melhor suporte à vida (água e terra). Nisto, a agricultura foi desenvolvida como fator determinante para a fixação humana. Há uma nova modalidade de trabalho, o agrícola, que redesenhará a sociedade humana.

Ainda no entendimento de Mota (2020) o novo modelo social agrícola que redefiniu o papel de cada pessoa nele, expandiu a concepção do trabalho como algo individual ou familiar para algo coletivo, conferindo-lhe um processo (plantio e colheita), obrigação (papel social) e remuneração (subsistência pessoal ou coletiva).

Esta compreensão já permite delinear a evolução histórica do trabalho como algo intrínseco à natureza humana (interagir e transformar a realidade). Talvez, esta concepção primeira do trabalho na era pré-histórica seja diferente de uma concepção já citada do trabalho como um castigo, alheio à vida humana e imposto por terceiros. Entretanto, cabe avançar na evolução histórica para ampliar o entendimento das diferentes percepções acerca do trabalho e as transformações tecnológicas e no processo produtivo que culminaram no atual teletrabalho. 
O período histórico conhecido como Idade Antiga, vai de 4 mil anos a.C., até o começo da Idade Média, século V d.C. Neste período já está desenvolvida a agricultura e a pecuária, o domínio do fogo para a transformação dos metais e a escrita. Já existe um perfil tecnológico que relaciona-se ao trabalho. Veschi (2019) irá sustentar que o trabalho já apresentava forte divisão social, destacando-se os artesões, os militares, a produção de alimentos e o trabalho escravo. A utilização de mão de obra escravizada para diversos trabalhos pode ter contribuído para a percepção do trabalho como algo penoso, de escravos, de pobres, ou como uma atividade reservada apenas para determinado seguimento social.

Importantes considerações podem ser feitas neste período, segundo Veschi (2019), Martins (200o) e Ornellas e Monteiro (2006). O trabalho permeia toda a sociedade humana de forma hierarquizada, desigual, com diferentes remunerações. Se o trabalho escravo era imposto a determinados grupos sociais, o relativo ao artesanato não seguia a mesma lógica. Geralmente relacionado com um núcleo familiar, era desenvolvido como forma de sobrevivência que não possuía a mesma obrigatoriedade do trabalho escravo ou militar.

É conveniente detalhar que o trabalho dos artesãos era aplicado em diferentes contextos até, com o tempo, atingir as especializações como carpinteiro, serralheiro, pintor, escultor, padeiro, confeiteiro, ceramista e as diferentes ações manuais que significam o domínio de determinada técnica.

Ainda para os efeitos de compreender a evolução histórica do trabalho, é importante entender que ele se naturaliza socialmente como algo integrante à ação humana (como de fato o é ao analisar a pré-história). O trabalho foi aceito com o algo obrigatório no sentido do uso de mão de obra escravizada ou na busca de sobrevivência, ou como algo do qual a organização social não pode prescindir (militares, agricultores).

Já no período histórico conhecido como Idade Média, dos séculos V a.C., até XV a.C., o trabalho vai ampliar as significações dos períodos anteriores, porém com significativos avanços no que se refere a tecnologia aplicada ao mesmo.

$\mathrm{Na}$ Idade Média persiste a figura do trabalho escravo, obrigatório e evidentemente assumido como um castigo e penoso. Há o trabalho agrícola e militar, entendido como fonte de subsistência ou lucro pessoal ou para o senhor feudal, ou obrigação coletiva (necessário ao bem da comunidade). No contexto medieval há uma série de transformações no trabalho 
que permitem a expansão dos feudos até o surgimento das novas cidades, bem como a criação do sistema bancário que sustentará o mercantilismo e o futuro capitalismo.

Será neste período histórico que as bases da estrutura acerca da sociedade e do trabalho moderno irão ganhar contornos mais próximos ao entendimento contemporâneo.

Para compreender as mudanças no trabalho que culminaram em um novo modelo de sociedade, vale ressaltar as inovações tecnológicas do período também entendidas como a interação da humanidade com ferramentas que irão acelerar os processos produtivos, o que mais tarde será assumido na digitalização de atividades e nas ações remotas mediadas pela técnica.

As inovações tecnológicas do período que aceleraram os processos produtivos são um novo sistema de atrelamento dos cavalos, a charrua e o moinho hidráulico.

O novo processo de atrelamento dos cavalos, saindo do pescoço (que os sufocava) e indo para o ombro, garantiu maior tempo de utilização do animal bem como velocidade de trabalho. $\mathrm{O}$ mesmo se deu com a criação da charrua utilizando uma estrutura de madeira com uma ponta metálica na aragem do solo que, ao aumentar a velocidade, permitiu o trabalho em uma extensão maior da terra. Também o moinho hidráulico e o de vento caracterizam-se como protótipos dos sistemas de automação modernos, onde o movimento dos elementos naturais era mecanicamente convertido para o funcionamento da moagem que já não dependia mais da ação humana direta no processo (MARTON, 2020).

Marton (2020) aponta ainda para outras inovações tecnológicas que impactaram nos processos produtivos medievais como o relógio mecânico, protótipos de catapultas e metralhadoras, o estribo, e os autômatos, considerados robôs medievais. Segundo Toniolo (202I) estas inovações medievais permitiram o surgimento e o desenvolvimento de princípios mecânicos que eclodiram na Revolução Industrial.

A invenção da máquina a vapor em 1968 por Thomas Newcomen representou uma nova era para o trabalho humano, bem como a aplicação de novos instrumentos tecnológicos que aceleraram ainda mais os processos produtivos. Relacionando a Revolução Industrial com os períodos históricos anteriores já analisados, é notável como o trabalho surgido na necessidade de sobrevivência e subsistência na pré-história assume um contorno totalmente 
social nas eras posteriores. O trabalho tornou-se parte do fazer humano, coletivizado, assumindo características distintas para as diferentes classes sociais.

A tecnologia foi se alterando a cada momento histórico, ora como uma técnica no fazer, ora como a construção de ferramentas mecânicas quase autônomas para um avanço considerável no século XVIII.

Oliveira (200I) considera a Revolução Industrial um período de grandes transformações sociais, o trabalho se modifica em escala industrial, provocando o êxodo rural, adensamento urbano e condições de trabalho precárias, com várias consequências sociais. Também irão dividir a Revolução Industrial em várias revoluções, com uma variação da matriz energética. Assim, a primeira Revolução ocorreu na Inglaterra, no século XVIII, usando o vapor de água para acionar engrenagens mecânicas aplicadas à produção/transformação de produtos. A segunda Revolução Industrial ocorreu no século XIX e o vapor de água foi substituído pela queima de combustíveis fósseis, no caso o petróleo e também o uso da energia nuclear (século XX).

Para compreender os elementos que interconectam as duas primeiras revoluções industriais basta compreender que uma fonte de energia movia um aparato mecânico para que produzisse/transformasse um determinado produto. Se até o fim da Idade Média a força humana e animal era utilizada na produção de bens, logo ela foi substituída pela eólica e hidráulica (natureza) para o mesmo tipo de produção.

Já no século XX ocorreu a terceira Revolução Industrial propiciada pela tecnologia computacional e avanços na genética, culminando na quarta Revolução Industrial chamada de Indústria 4.o, onde o uso de redes, sensores e processos automatizados aceleraram os processos produtivos tornando-os mundiais e novamente transformando as relações de trabalho.

Basicamente, o mesmo princípio que norteava o uso da máquina a vapor continua presente hoje nas termoelétricas.

O uso da energia elétrica logo substituí em grande parte o uso de combustíveis ou a força humana ou da natureza nas máquinas relacionadas aos processos industriais. Logo, no século $\mathrm{XX}$, com o surgimento dos computadores e redes, bem com o aprimoramento de softwares, irá ocorrer um processo de especialização das ferramentas produtivas intitulado 
automação, que, ao menos em princípio, ocorria parcialmente com o uso das diferentes máquinas industriais do passado. Entretanto, a automação do século XX e XXI assume um contorno distinto, onde há cada vez menos a participação humana no processo, que é modificada apenas para um papel de planejar, fiscalizar ou manter um pátio tecnológico em total funcionamento presencial ou remotamente.

A Revolução Digital ou Tecnológica é também compreendida como a $4^{\underline{a}}$ Revolução Industrial, relativa aos aprimoramentos nos processos produtivos gerados pelas diferentes alterações de matrizes energéticas e métodos de produção associados à computação e aos avanços em hardware e software, em uma sociedade em rede e altamente digital. Neste sentido, a tecnologia industrial contemporânea distancia-se em muito dos modelos anteriores, em velocidade, acesso aos dados, modelos de prognósticos e sistemas automatizados.

Zanardi e Okada (2019) ressaltam as várias características acerca desta quarta revolução que basicamente, por meio da tecnologia, é impulsionada na fabricação de elementos físicos e virtuais, de forma veloz e praticamente ajustada à demanda dos consumidores que estão em todos os lugares do planeta. Há uma produção inteligente e ubíqua.

Outras características apontadas por Zanardi e Okada (2019) e Silva (2018) são as seguintes: a Inteligência Artificial; A Internet das Coisas; a robótica; a realidade aumentada e a realidade virtual; a gestão e interpretação de dados; a impressão em ${ }_{3} \mathrm{D}$ e ${ }_{4} \mathrm{D}$. Aplicadas à indústria, tais características representam de fato uma revolução nos processos industriais no que tange à automatização de processos. Tanto a Inteligência Artificial quanto à Internet das coisas aplicadas à Robótica permite processos de automatização na produção onde basicamente, uma indústria operará utilizando computadores e máquinas supervisionados ou gerenciados pela ação humana. Já é o que se percebe na contemporaneidade em grandes plantas industriais.

Elementos relacionados à lógica de programação associados ao poder computacional (processamento de dados), tornam os processos já automatizados em inteligentes, adaptáveis e em sincronia com diferentes partes ao redor do mundo, onde o processo de 
fabricação pode ser simultâneo e preciso, no sentido de fabricar um produto com distintas partes e materiais não localizados geograficamente no mesmo lugar.

Conforme apontam Silva e Cardoso (2021) além dos impactos diretos na produção, a tecnologia contribui para que a gestão empresarial se torne mais eficaz, pois “o sensoriamento e a análise de dados para a tomada de decisão em tempo real, vem se tornando essenciais para tomada de decisão e acompanhamento da linha de produção [...] seu crescimento vem ampliando e tornando-se mais sólido ao longo do tempo.”

Levando em consideração a evolução do trabalho e os avanços tecnológicos a ele associados, bem como o incremento do poder computacional e das redes de comunicação, o contexto contemporâneo apresenta uma nova modalidade laboral que é o teletrabalho.

Lima Filho e Brasil (2019) argumentam que o teletrabalho já era debatido e implementado fora do Brasil nos últimos anos por apresentar flexibilidade e comodidade para empregadores e funcionários. Determinadas atividades essencialmente técnicas, artísticas, analíticas, de gestão ou correlatas podem prescindir da presença do funcionário na empresa justamente por se realizarem de forma tecnológica, mediadas pela computação e redes de dados. Tais atividades que se realizam pelo computador podem ser remotas pela ampliação das redes e sua capacidade de transmissão.

A Lei número 13.467 (BRASIL, 2017) em seu artigo $75^{\circ} \mathrm{B}$ preconiza que o teletrabalho é "a prestação de serviços preponderantemente fora das dependências do empregador, com a utilização de tecnologias de informação e de comunicação que, por sua natureza, não se constituam como trabalho externo." Na compreensão da lei, vale ressaltar que o teletrabalho é uma forma ou modalidade de trabalho feita remotamente (fora da empresa) mediada por instrumentos tecnológicos (computadores - redes de comunicação).

Tal modalidade de trabalho apresenta-se como uma evolução que se incrementou ao longo das eras, desde o telégrafo, fax, televisão e recentemente a Internet e dispositivos como computadores, notebooks, tablets e smartphones. É oportuno levar em consideração a diversificação do trabalho no contexto contemporâneo e sua contínua especialização. Neste sentido, quanto mais o trabalho se torna automatizado, maior é o uso de tecnologias na sua execução, gestão e análise. 
De certa forma, muitas das atividades laborais tem uma relação estreita com a tecnologia, mesmo quando tal relação não é explícita. Quando o trabalhador que, por exemplo, realiza atividades manuais deve registrar a entrada e saída de alguma forma, mesmo manual, possivelmente acabará transformada em dados digitais. Quando não, a gerência do seu tempo de trabalho, pagamento, férias, impostos, ocorrências e sinistros acabam tendo uma mediação tecnológica (planilhas, transferências de fundos, envio de dados ao governo).

É justamente nesta relação que o teletrabalho surge, já não mais operando implicitamente na atividade laboral, e sim explicitamente, pois é a tecnologia que permite que o trabalho seja realizado. A tecnologia se apresenta como elemento fundamental para a realização do trabalho, fazendo parte de sua essência.

O teletrabalho é diferente do trabalho em domicílio. Este último ocorre sem a supervisão do empregador ou uma mediação tecnológica com a empresa para que ocorra. Como exemplo de trabalho em domicílio pode-se citar as costureiras que trabalham em casa para o posterior envio do material para o empregador ou venda do mesmo para um comprador ou contratante do serviço. No caso do teletrabalho ele ocorre intermediado pela tecnologia em uma tarefa relacionada, ou conectada, à empresa. Por exemplo, um gestor que analise planilhas de gestão, performance ou rendimentos usa o computador e a rede para acessar a rede da empresa e seu servidor ou banco de dados para analisar as informações.

$\mathrm{Ou}$, em outro caso, por meio de um fluxo de dados por e-mail ele pode consultar ou oferecer informações, bem como receber e analisar dados que podem ser enviados por meio de planilhas ou outros formatos digitais. $\mathrm{O}$ mesmo se estende para um engenheiro ao compilar uma planta, um artista para a criação e a elaboração de projetos ou até mesmo um analista que deve apresentar as suas considerações em relação a determinados assuntos. $O$ teletrabalho mantém um vínculo síncrono ou assíncrono de dados com o empregador, sempre mediado por um instrumento tecnológico executado por meio de uma rede de dados (Internet).

Com a atual pandemia do novo coronavírus Sars-Cov-2 (COVIDıg) e a paralização de muitas atividades, foi necessário repensar os modelos e formatos de trabalho. Neste 
contexto o teletrabalho ganha relevância pela urgência de continuar prestando serviços em meio ao distanciamento social.

A pandemia provocou a busca por alternativas diversas para dar continuidade à vários serviços laborais que já praticavam um hibridismo no formato presencial-remoto. Um exemplo disso foi a educação que já possuía uma série de plataformas para o ensino à distância (EAD). Tais plataformas trabalhavam de forma síncrona ou assíncrona como os alunos. Entretanto, durante a pandemia os profissionais que trabalhavam de forma presencial tiveram que buscar alternativas para oportunizar uma educação não presencial. Muitos se valeram das redes sociais ou aplicativos de mensagens, vídeos ou videoconferências. Outros usaram as plataformas pedagógicas já existentes.

Também pequenos e médios empresários foram provocados a usar as redes sociais para comunicar-se com seus consumidores e oferecer serviços de delivery. O próprio governo aprimorou plataformas e aplicativos para oferecer serviços e se comunicar com a população. Neste sentido é permitido compreender que as atividades remotas mediadas pela tecnologia, entre elas o teletrabalho, foram forçosamente incrementadas pela pandemia do novo coronavírus.

Lima (2020) apresenta algumas vantagens e desvantagens do teletrabalho. Como vantagens pode haver uma flexibilidade maior na jornada de trabalho, economia de tempo, pois não há necessidade de deslocamento até a empresa sobrando tempo para outras atividades e diminuindo o fluxo de trânsito. O empregador economiza por não necessitar de uma estrutura física para a execução do trabalho, apenas o investimento em tec nologias que permitam aos trabalhadores executarem as tarefas remotamente. Já como pontos negativos, a excessiva jornada de trabalho em frente a um computador pode gerar doenças relacionadas aos músculos e a visão, a falta de socialização, a ausência do espaço privado (sua casacomputador torna-se "parte da empresa") e a dificuldade de mobilização dos trabalhadores para demandas em comum.

Entretanto cabe ressaltar, assim como o trabalho evolui desde a pré-história até os dias atuais, pode-se com sinceridade assumir que o teletrabalho atual ainda está em fase de adaptação e normatização e também passará por transformações em seu formato, a medida em que avançam os instrumentos tecnológicos. 


\section{REFERÊNCIAS}

BASTOS, Antônio Virgílio; PINHO, Ana Paula Moreno; COSTA, Clériston Alves. Significado do Trabalho: um estudo entre trabalhadores inseridos em organizações formais. Fundação Getúlio Vargas (FGV), Revista de Administração de Empresas, São Paulo, v. 35, n. 6, p. 20-29, nov./dez., 1995. Disponível em: 〈https://www.scielo.br/j/rae/a/ZrvqCwgjTx9SKSsGhzwPH8R/?lang=pt〉 Acesso: is jul, 2021.

BÍBLIA. João Ferreira de Almeida. Gêneses. SBB: Brasília, I969.

BRASIL. Presidência da República. Lei no 13.467, de 13 de julho de 2017.. Disponível em: 〈http://www.planalto.gov.br/ccivil_03/_ato2015-2018/2017/lei/li3467.htm〉 Acesso: is jul, 2021.

CAIUSCA, Alana. Paleolítico. Portal Guia de Estudo, Artigo, 2or8. Disponível em: 〈https://www.guiaestudo.com.br/paleolitico/amp〉 Acesso: I5 jul, 202I.

LIMA, Hugo Ferreira de. O teletrabalho e a pandemia do Covid-r9. 25 f. 2020. Pontifícia Universidade Católica de Goiás, Artigo. Disponível em: 〈https://repositorio.pucgoias.edu.br/jspui/bitstream/123456789/1346/2/O\%20TELETRAB ALHO\%20E\%20A\%2oPANDEMIA\%20DO\%20COVID-r9.pdf> Acesso: 15 jul, 2021.

LIMA FILHO, José Sarto Fulgêncio de; BRASIL, Ana Larissa da Silva. O conceito legal de teletrabalho e sias repercussões nos direitos do empregado. Revista Juris UniToledo, Araçatuba, Artigo, v. 4, n. I, p. III-I26, jan./mar, 2019. Disponível em: 〈http://www.mpsp.mp.br/portal/page/portal/documentacao_e_divulgacao/doc_biblioteca /bibli_servicos_produtos/bibli_boletim/bibli_bol_2006/Rev-Juris-

UNITOLEDO_v.4_n.I.o8.pdf> Acesso: 15 jul, 202I.

LARA, Bruno. Trabalho: dor e felicidade. Universidade de Brasília (UNB), Notícias, 2019. Disponível em: 〈https://noticias.unb.br/artigos-main/3151-trabalho-dor-e-felicidade> Acesso: 15 jul, 2021.

MARTINS, Sérgio Pinto. Breve histórico a respeito do direito do trabalho. Revista da Faculdade de Direito da Universidade de São Paulo, São Paulo, v. 95, p. 167-176, 2000.

MARTON, Fábio. Grandes invenções da Idade Média. Portal Abril Editora, Revista Super Interessante, Artigo, 2020. Disponível em: 〈https://super.abril.com.br/historia/grandesinvencoes-da-idade-media/> Acesso: 15 jul, 2021.

MOTA, P. H. Neolítico - o que foi e quais mudanças provocou na sociedade. Portal Conhecimento Científico, $\mathrm{R}_{7}$, Artigo, 2020. Disponível em: <https://conhecimentocientifico.r7.com/neolitico-2/> Acesso: I5 jul, 202I 
NEVES, Diana Rebello; NASCIMENTO, Rejane Prevot; FÉLIX JÚNIOR, Mauro Sérgio; SILVA, Fabiano Arruda da; ANDRADE, Rui Otávio Bernardes de. Sentido e significado do trabalho: uma análise dos artigos publicados em periódicos associados à Scientific Periodicals Eletronic Library. Cadernos EBAPE.BR, Rio de Janeiro, v. ı6, n. 2, abr./jun., 2018. 〈https://www.scielo.br/j/cebape/a/ncWvqK58zG8PqZC5ZQCGz9x/?lang=pt〉 Acesso: is jul, 202I.

OLIVEIRA, Ana Cristina Salibe Baptistella de. A evolução do processo produtivo e as novas competências do trabalhador. 283 f. 2001. Universidade Estadual de Campinas (UNICAMP), Faculdade de Educação, Tese (Doutorado). Disponível em: 〈http://repositorio.unicamp.br/bitstream/REPOSIP/2534I3/I/Oliveira_AnaCristinaBapti stellade_D.pdf> Acesso: I5 jul, 202I.

ORNELLAS, Thuê Camargo Ferraz de; MONTEIRO, Maria Inês. Aspectos históricos, culturais e sociais do trabalho. Revista Brasileira de Enfermagem, v. 59, n. 4, p. 552-555, 2006. Disponível em: 〈https://www.scielo.br/j/reben/a/HqyzDDq4GTJRvYmjJkMwqcq/abstract/?lang=pt> Acesso: 15 jul, 2021.

PEREIRA, Andréa Renê. Evolução do Trabalho e o trabalho em tempos globalizados. Portal Estudos do Trabalho, Artigo, 2021? Disponível em: 〈http://www.estudosdotrabalho.org/anais6seminariodotrabalho/andrearenepereira.pdf > Acesso: 15 jul, 2021.

ROSA, Augusto Pereira da; ZINGANO, Ester Miriane. Pré-História: educação para a sobrevivência. UNIASSELVI, Revista Maiêutica, a. I, n. I, 2013. Disponível em: 〈https://publicacao.uniasselvi.com.br/index.php/ART_EaD/article/download/314/58>

Acesso: 15 jul, 2021.

SILVA, Nelson. Transformação Digital, a $4^{\mathbf{a}}$ Revolução Industrial. Fundação Getúlio Vargas, FGV Energia, Caderno Opinião, Artigo, 2or8. Disponível em: <https://fgvenergia.fgv.br/sites/fgvenergia.fgv.br/files/coluna_opiniao__transformacao_digital.pdf> Acesso: 15 jul, 202.

SILVA, Solimar Teixeira da; CARDOSO, Simere Mendes. A Influência da tecnologia na produção e competitividade das empresas. Portal Senais, Artigo, 2021? Disponível em: $\langle$ https://senaies.com.br/news/artigo-a-influencia-da-tecnologia-na-producao-ecompetitividade-das-empresas/> Acesso: I5 jul, 202I.

TONIOLO, Ênio José. O progresso técnico da Idade Média. Instituto Nacional de Pesquisas Espaciais (INPE), Divisão de Astrofísica, Artigo, 2021? Disponível em: 〈http://www.das.inpe.br/ alex/Ensino/cursos/historia_da_ciencia/artigos/tecnica_na_ida de_media_42.pdf> Acesso: 15 jul, 2021.

UFRGS. Universidade Federal do Rio Grande do Sul. A Etimologia do Trabalho. Portal da UFRGS, 2021? Disponível em: <https://etimologia.com.br/trabalho/> Acesso: I5 jul, 202I. 
VESCHI, Benjamin. Etimologia de Trabalho. Portal Etimologia, 2019. Disponível em: <https://etimologia.com.br/trabalho/> Acesso: I5 jul, 2021.

ZANARDI, André Luiz; OKADA, Roberto Hirochi. Transformação Digital na Indústria: $4^{\underline{a}}$ revolução industrial. Faculdade de Tecnologia de Garça (FATECGARCA), Artigo 202I? Disponível em: 〈https://fatecgarca.edu.br/ojs/index.php/efatec/article/download/I7I/I53/> Acesso: is jul, 2021. 